\title{
On Translation Equivalence from the Perspective of Cultural Gaps
}

\author{
Lei DAI \\ Department of Translation and Interpretation, School of Foreign Languages, Wuhan University of \\ Technology, Wuhan, China \\ dailei218@whut.edu.cn
}

Keywords: Equivalence, Translatability, Cultural Gaps.

\begin{abstract}
Translation is intrinsically not only inter-lingual but also intercultural communication. So exploration of how to translate will inevitably touch upon the cultural gaps. In fact, the substantial challenge with translation derives far more from the cultural than the linguistic dimension. Judging from the linguistic viewpoint everything seems translatable. However, intercultural barriers and gaps are sometimes insurmountable with the translator reluctantly omitting the untranslatable part of the source text. This paper thus investigates equivalence, translatability and untranslatability from the perspective of cultural gaps, with the findings that due to the instability of meaning constituted by a myriad of contextual, textual and personal factors, the equivalence identified from a translation act may not be replicated in / applied to other translation acts. The main argument is that equivalence in translation should be dynamic and translatability is only relative in specific contexts.
\end{abstract}

\section{Introduction}

"Translation is in nature not only an interlingual act but more importantly a type of intercultural communication". [1,2]. Therefore, the exploration of how to translate will inevitably touch upon "the difficulties / barriers / noises / gaps" [3] caused by such intercultural communication. In fact, the substantial challenge with translation derives far more from the cultural than the linguistic dimension. Judging from the linguistic viewpoint pitifully everything seems translatable. However, intercultural barriers and gaps are sometimes indomitable with the translator reluctantly omitting the untranslatable part of the source text. This paper will thus investigate equivalence, translatability and untranslatability from the perspective of cultural gaps.

\section{Translation Strategies from the Perspective of Cultural Gaps}

Wilss claims [4] that in order to evaluate if the source cultural features can be translated, the translator should consider the degree to which they can be integrated into the target language by combining linguistic factors with extra-linguistic factors. The existence of cultural conversions and omissions, fundamentally speaking, derive from the incompatibilities of different cultures in different contexts. To facilitate communication, some of the source cultural images and references prone to cause misunderstanding or contradictions have to be modified, replaced or even omitted "to adapt to the tastes / needs / anticipation of the target receptors" [5]. Additionally, the elegant, rhyming idiomatic expressions familiar to a nation cannot be entirely transplanted into another culture since "translation per se is a filtering process" [2], during which, part of the source linguistic forms and the cultural features will be lost. However, it is because the translator decisively gives up translating faithfully those source cultural expressions otherwise impeding communication, the essential meaning of the source text is delivered completely, coherently, naturally and quickly with the readers' cognition and aesthetics attended.

\section{Reflections upon the Controversies over Equivalence in Translation Studies}

"One of the most controversial issues of Translation Studies is equivalence" [6], with each contemporary translation theory contributing its unique perspective: as TT-ST syntactic and lexical 
correspondences by the structural linguists; as principally semantic correspondences by the Paris interpretive school; as functional correspondences by the dynamic-and-formal equivalence theory and the skopos theory, to name just a few. Such debates have culminated recently in the downright deconstruction of the notion by postmodernists as they argue that "meaning itself is not static or fixed but fluid, abstract, context-dependent and can be interpreted and reinterpreted in numerous ways" [7] which has echoed what the culturalists claim "the indeterminacy of meaning" [8] and what Pym observed [6] "the epistemological skepticism" that no one can safely assert that they have found the only best way of translation for a specific text.

However, despite the criticisms towards equivalence that relegate it to "a prehistoric relic from an era prior to the rise of Translation Studies" [9], "a thing of the past" [10] and "a blanket concept used for the sake of convenience" [11], it is argued by the researcher of this thesis that equivalence should still be taken into account as an important concept when analyzing translation products as well as designing translation processes in which translation strategies are selected. This notion cannot be rejected simply because of the instability of meaning. Admittedly, it is apparent that "meaning is not always stable and definitely fixed in a text, that reader response cannot be fully evaluated and controlled and that, translations often have radically different functions from their sources" [12]. But equivalence as the researcher argues should be a cluster concept, by achieving which, a full range of contextual, textual and personal factors should be considered, such as the functions of both the source and target texts, the reader response, the translator's own subjective intervention and above all the dynamic sociocultural contexts where the translation act takes place, just as Simon has admonished [13] "the question of equivalence cannot be decided once and for all".

All these discussions boil down to a plain fact that "the equivalence of translation is not defined a priori but profiled through a descriptive process" [14]. As Williams [12] observed: "Translation scholars are no longer interested in a priori definitions of what could or could not constitute equivalence, but rather in establishing the actual relations of equivalence between a particular TT and ST in a particular place and at a particular time".

Therefore, any research on translation strategies which are selected in order to achieve an optimal equivalence between TT-ST pairs should be carried out "through describing and explaining what translators do, what strategies they use and what roles they play under the given sociocultural and linguistic conditions" [15]. This is actually the descriptive translation studies devised by Toury who devised a postulate whereby equivalence is "a descriptive term, denoting concrete objects - actual relationship between actual utterances in two languages" [16]. In other words, due to the instability of meaning constituted by a myriad of contextual, textual and personal factors, the equivalence discovered from a certain translation act may not be replicated in / applied to other translation acts. Just as Tymoczko argued [7], "it is rather difficult to imagine that the interpreting norms inducted from an illiterate population in South Africa can be applied to literary or audiovisual translation in Europe".

\section{Review upon (un) Translatability}

It is argued in this paper that the instability of equivalence and the indeterminacy of meaning that have been discussed above jointly justify the existence of the omitting strategy. More specifically, since a target text cannot always be equivalent to a source text, something will now and then miss out of the translation which results from a purposeful or reluctant choice made by the translator. When this happens, the text is considered partially translatable because those source information omitted by the translator is at the same time untranslatable.

For instance, Catford [17] once illustrated untranslatability by pointing out that the French feminine plural pronoun "elles" (them: a group of females) cannot be fully translated by "them / they" in English. The information lost here in translation can be deemed as a reluctant choice made by the translator which results from the linguistic differences between French and English. For another instance, when the negotiating parties are in disputes, even using profanities emotionally, the 
interpreter may have to dismiss the nasty information so as to ease the atmosphere. It would be insensible of the interpreter to interpret loyally everything the negotiators have said. In this case, the interpreter deliberately uses the omitting strategy.

Besides, omitting may be a choice due to the influence of ideology. Lefevere's case [18] shows how the German translation of The Diary of Anne Frank deliberately deleted some of Anne's harsh words against Nazi's atrocities to the Jews, thus rewriting Anne Frank's diary to pander to the public discourse of the mid 1950s when Germany was desperately struggling to escape its Nazi shadow. Thus, the existence of untranslatability due to the instability of equivalence and indeterminacy of meaning justifies the necessity of taking omitting as an important translation strategy.

However, it is argued by the researcher that (un)translatability is intrinsically a notion as fluid as meaning and something translatable in a given context may become untranslatable in another. The notion may also become controversial within the subject of Translation Studies because interpreting differs in the working mode from translating. For instance, the dynamic-formal equivalence theory admits the existence of untranslatability because the pursuit of the simultaneously functional and formal equivalence is more often than not unrealistic. On one hand, Nida emphasized [5] that dynamic equivalence is a kind of natural equivalence closest to the source information, "conveying the spirit and manner of the original" [5]. On the other hand, he stressed that the target text should read "natural", "coherent" and the "foreignness" of the ST setting is minimized [5], with a clear preference for domesticating. Evidently, the two appeals may seem contradictory because languages and cultures are different around the world and this issue becomes more prominent when it comes to "English and Chinese whose conceptual structure may differ crucially" [19].

In other words, it is rather difficult if not impossible to at the same time translate in TL the spirit and manner of the Chinese culture-specific expressions and, re-express in the typically British / American way. Intrinsically, the paradox lies in the contradiction of attempting to use foreignizing and domesticating both at the same time. Therefore, Nida considers [5] translatability as only relative and that "the correspondence in meaning must have priority over correspondence in style". That also explains why this thesis described the translation process as the translator perching between the ST and TT and, the speaker and the audience. By contrast, the interpretive theory of translation deems everything translatable given the working mode of interpreting. Without taking full account of equivalence of linguistic forms, the interpretive theory actually gives top and almost exclusive priority to the kind of equivalence that Nida named as dynamic equivalence. The interpreter only needs to convey to receptors "meaning, function, cognition, emotions" [20] of the source text to guarantee the fluency of communication. So from this perspective, everything is translatable.

\section{A Case Study}

Li Jiangchun [21] once exemplified the use of omitting in interpreting. In a lecture, the speaker told a rather obscure joke that could not easily make sense to the target receptors, or in other words, the first three translation strategies foreignizing, domesticating and clarifying could not work. The interpreter, in order to make the audience laugh (i.e. to achieve a similar response), interpreted it as "Just now the speaker told us a very funny story, please laugh!" which did take effect! Li claimed that this way of interpreting in the specific context is time-saving and effective.

It should be noted that when discussing translation strategies, translatability and untranslatability, there should be an ideal prerequisite: the translator should be professionally qualified / accredited, responsible and comply with professional ethics. Otherwise, when analyzing the three concepts, incomparability will rise. For instance, for a unqualified translator, much of the translatable information may be considered untranslatable because of her inadequate bilingual proficiency and defects in knowledge structure. The interpretation in Li's example (2012:37-38) is considered viable only on the premises that the interpreter is qualified and the joke is truly untranslatable under the given context. It is evaluated a success because the basic function of the source text is achieved, as evidenced by the laughter from the audience. On the contrary, if the interpreter is problematic and 
often interprets nonsense, there then is no way to judge her performance and her selection of the translation strategies simply because the object of the laughter may not be the joke but the interpreter.

\section{Conclusion}

In overall terms, such key notions as equivalence and translatability in Translation Studies have been critically reviewed in this paper which at the same time justifies the omitting strategy used by interpreters and translators. As Cronin posited [22], "Translation Studies centers on differences; without differences, the subject turns largely invalid". The existence of linguistic and cultural differences between the source text and the target text determines the untranslatability of certain linguistic and cultural issues. Moreover, "the interpreter / translator as human beings will invariably instill their subjectivity into translation and interpreting" [12] that are essentially concerned with the transfer of "meaning which is undeterministic" $[6,8]$. The indeterminacy of meaning and instability of equivalence therefore exhorts translation researchers to study translation through the descriptive perspective, namely the translation products to find the corresponding translation norms. Concerning translators and interpreters, they should be alert of the cultural gaps involved in the source text and adeptly circumvent them so as to facilitate intercultural communication.

\section{Acknowledgement}

This research was financially supported by the Fundamental Research Funds for the Central Universities, PRC on the program "On the Foreignizing Translation Trend from the Perspective of Cultural Turn" (program code: 20110831).

\section{References}

[1] J. Chen, Strategies for Abating Intercultural Noise in Interpreting, Meta. 3(2007) 529-541.

[2] D. Katan, Translation as Intercultural Communication, in J. Munday (Eds.), The Routledge Companion to Translation Studies, Routledge, Oxford, 2009, pp.74-92.

[3] J. Zhao, N. Jiang, On Interpreters' Intercultural Awareness, Chinese Science and Technology Translators Journal. 2(1998) 31-38.

[4] W. Wilss, the Science of Translation: Problems and Methods, Gunter Narr Verlag, Tubingen, 1982.

[5] E.A. Nida, Toward a Science of Translating, E. J. Brill, Leiden, 1964.

[6] A. Pym, Exploring Translation Theories, second ed. Routlege, London and New York, 2014.

[7] M.Tymoczko, Enlarging Translation, Empowering Translators, St Jerome, Manchester, 2007.

[8] C. Marinetti, Cultural Approaches, in Y. Gambier, L. van Doorslaer (Eds.), Handbook of Translation Studies, volume 2, John Benjamins, Amsterdam and Philadelphia, 2011, pp.26-31.

[9] K. Koskinen, How to Research EU Translation? Perspectives, 4(2001) 293-300.

[10] B. Hatim, Teaching and Researching Translation, Pearson Education, Harlow, 2013.

[11] M. Baker, In Other Words: A Coursebook on Translation, Routledge, London and New York, 2011.

[12] J. Williams, Theories of Translation, Palgrave Macmillan, New York, 2013.

[13] S. Simon, Gender in Translation: Cultural Identity and the Politics of Transmission, Routledge, London and New York, 1996. 
[14] A.A. Rosa, Descriptive Translation Studies, in Y. Gambier, L. van Doorslaer (Eds.), Handbook of Translation Studies, volume 2, John Benjamins, Amsterdam and Philadelphia, 2011, pp.94-104.

[15] A. Chesterman, What Constitutes "Progress" in Translation Studies? in B. Englund-Dimitrova (Eds.), Oversättning och tolkning: rapport fran ASLA: Höstsymposium, Stockholm, 5-6 november 1998, Uppsala: Asia, pp.33-49.

[16] G. Toury, In Search of a Theory of Translation, the Porter Institute, Tel Aviv, 1980.

[17] J.C. Catford, a Linguistic Theory of Translation, Oxford University Press, London, 1965.

[18] A. Lefevere, Translation, Rewriting, and the Manipulation of Literary Fame, Routledge, London and New York, 1992.

[19] J. Munday, Introducing Translation Studies: Theories and Applications, Routledge, London and New York, 2012.

[20] M. Lederer, Translation: The Interpretive Model. St. Jerome, Manchester, 2003.

[21] J. Li, On Strategies for Chinese-English Interpreting from the Perspective of "E" in Interpreting, Chinese Science and Technology Translators Journal, 1(2012) 36-38.

[22] M. Cronin, Translation and Globalization, Routledge, London and New York, 2003. 